\title{
More lessons from linalool: insights gained from a ubiquitous floral volatile
}

Robert A. Raguso ${ }^{1,2}$

${ }^{1}$ Dept. of Neurobiology and Behavior, Cornell University, 215 Tower Rd., Ithaca, NY 14853

USA

${ }^{2}$ Corresponding author: rar229@ cornell.edu

\begin{abstract}
Linalool (3,7-dimethyl-1,6-octadien-3-ol) is a common floral volatile with two distinct enantiomers and related metabolites involved in the full spectrum of plant-pollinator interactions. Recent studies reveal a complex interplay between pollinator attraction and plant defense mediated by linalool and its derivatives, from the smallest (Arabidopsis, Mitella) to the largest (Datura) flowers studied. Accordingly, fig wasps, fungus gnats and moths of all sizes show remarkable electrophysiological, neural and behavioral sensitivity to different enantiomers and quantitative ratios of linalool in floral bouquets. The diverse functions of linalool, ranging from toxin to long distance pollinator attractant are discussed in the broader context of floral volatile ecology and evolution.
\end{abstract}

\section{Introduction}

Scent remains the least understood dimension of floral phenotype, given the spatiotemporal dynamism of volatile emissions, the chemical toolkit and lexicon needed to characterize their 
composition, and the challenges of pinpointing their often scale- or context-dependent functions. Over 1700 volatile organic compounds (VOCs) have been identified from floral headspace [1], and more are discovered each year as researchers cast broader phylogenetic nets into the sea of phytochemical diversity [2,3]. In the face of such complexity, it is noteworthy that a small subset of VOCs (e.g. benzaldehyde, $\beta$-caryophyllene, limonene, methyl salicylate) is over-represented in floral scents, present in 50-70\% of all species studied to date [1] and encompassing a multitude of ecological functions [4,5]. Here I focus on a ubiquitous and multifunctional VOC, the monoterpene alcohol known as linalool (3,7-dimethyl-1,6-octadien-3-ol), building on an earlier review that dealt primarily with biosynthetic details [6]. Although linalool is a fascinating compound in its own right, here I treat it as a placeholder for common floral VOCs, by which to highlight recent advances and opportunities for further growth towards an integrated understanding of the biology of floral scent.

\section{Which linalool? A pair of enantiomers and their many derivatives}

In a chemical context, "linalool" is a misleading name because it implies a single compound where, in fact, there are two enantiomers, $(R)-(-)$ - and $(S)-(+)$-linalool, due to the hydroxyl bearing stereocenter at C-3 of 3,7-dimethyl-1,6-octadien-3-ol. The available evidence supports the semantic treatment of these enantiomers as separate entities, as they are chemically, biosynthetically, electrophysiologically and behaviorally distinct. The genes responsible for their production are members of the terpene synthase (tps) gene family, along with nearly all structural genes responsible for the biosynthesis of monoterpenoids in the tissues of higher plants [7,8]. However, tps sequences responsible for the biosynthesis of $(R)-(-)-$ and $(S)-(+)-$ linalool, 
respectively, do not cluster closely with each other, and thus represent multiple examples of convergent or parallel molecular evolution within a large multigene family across the angiosperms [9]. For example, in Arabidopsis thaliana, two enantiospecific enzymes (TPS10 and TPS14) produce $(R)-(-)$ - and $(S)-(+)-$ linalool, respectively, as their major products [10]. Linalool synthases often differ in spatial and temporal aspects of their expression, with LeMTS1 producing $(R)-(-)$-linalool in leaf trichomes of tomato (induced by spider mite herbivory) [9] and LIS producing $(S)-(+)$-linalool constitutively in flower petals of Clarkia breweri [6].

The double bonds and C-3 hydroxyl group that characterize the linalool skeleton make it vulnerable to further modification, including derivatization to the well-characterized furanoid and pyranoid linalool oxides common to wines, floral scents and papaya fruit $[11,12]$. Of these, the furanoid linalool oxides may give rise to 16 possible stereoisomeric aldehydes and alcohols, collectively known as "lilac compounds", owing to their discovery in the floral scent of Syringa vulgaris [13; see 52]. Lilac compounds attract specific functional groups of pollinators, such as noctuid moths $[14,15]$ and long tongued fungus gnats [16] in different floral contexts. Accordingly, these compounds have drawn the attention of pollination biologists, because in well-studied plant lineages such as Platanthera orchids, Silene and Mitella, lilac compounds mediate ecologically specialized pollination systems by attracting specific pollinator classes (Figure 1A).

However, lilac compounds do not function only as pollinator attractants. In the tiny, selfpollinating flowers of $A$. thaliana, lilac compounds contribute to an array of volatile and nonvolatile linalool metabolites. Both enantiomers of linalool (synthesized in plastids) are oxidized by two cytochrome P450 enzymes (CYP71B31 and CYP76C3, located in the endoplasmic reticulum) into several isomers of hydroxy- and epoxylinalool, some of which are converted to 
non-volatile conjugates [10]. Subsequent experiments revealed another p450 (CYP76C1) with high expression in floral tissues and the capacity to progressively oxidize the C-8 position of linalool to alcohol, aldehyde and acid forms, and (presumably through a furanoid intermediate) to lilac alcohols and aldehydes [17]. Why would an autogamous plant invest in such complex metabolism of a common floral VOC? Null mutants of $c y p 76 c 1$ show no inherent fitness costs (e.g. seed reduction) in the lab, so the authors suspected a defensive function against floral predators in nature. Choice bioassays using these mutants as well as synthetic VOCs revealed that thrips, generalist (Spodoptera littoralis) and specialist (Plutella xylostella) moth larvae all are attracted to linalool, but are repelled either by lilac compounds or by hydroxylinalools (Figure 1E, D). Thus, linalool metabolism in A. thaliana flowers is more germane to floral defense than to pollinator attraction (Fig. 1).

\section{Mixed messages: floral signals and cues in a whole-plant context}

The previous section ended with the caveat that floral volatile evolution can be driven by natural enemies as well as by pollinator-mediated selection [18]. Recent studies have revealed complex selective pressures on specific floral VOCs due to the interplay between pollinators and florivores, which would not have been appreciated without experimental manipulation of specific compounds in field settings [19,20,21]. Because linalool is nearly ubiquitous in flowers, it has been thought to function primarily as a pollinator attractant (Figure 1B), particularly in nightblooming flowers pollinated by hawkmoths [22,23], which are attracted even to low dosages of linalool in VOC blends [24]. However, hawkmoth larvae (hornworms) are herbivores, and female Manduca sexta, M. quinquemaculata and Hyles lineata moths frequently intersperse oviposition with nectar feeding when host plants provide floral nectar [25,26,27]. 
How might plants navigate a fitness landscape in which their primary or most effective pollinator may also be a destructive herbivore? Some plants stagger flowering and leaf flush, apparently in response to similar selective pressures [28], but this ecological strategy is not always an option. The herbivorous pollinator paradox has been addressed in a series of studies on the interactions between female $M$. sexta moths and Datura wrightii, their primary host plant and nectar source in the Sonoran Desert of North America [29]. Flowers of D. wrightii emit a complex VOC bouquet that includes small amounts of $(R)-(-)-$ and $(S)-(+)-$ linalool [30], which (along with other compounds) stimulate feeding by flower-naïve $M$. sexta [24]. Feeding responses to linalool are not enantioselective, but females lay more eggs in the presence of the $(S)-(+)$-enantiomer and fewer when $(R)-(-)$-linalool is present [30]. This result is consistent with the finding that adult $M$. sexta lay fewer eggs on tomato plants that emit $(R)-(-)$-linalool in a bouquet of VOCs released by leaf trichomes after damage by larval M. sexta [9,31].

As with Arabidopsis (see above), one benefit of model systems is the increased availability of background information to guide interpretation of ecological or behavioral results. Because $M$. sexta is a model system for the study of insect olfaction, a large body of neurophysiological studies provides context for understanding host choice by these moths (e.g. [32]). Earlier work on the neural organization of the $M$. sexta antennal lobes (AL) revealed a pair of unique glomeruli in female ALs, one of which receives inputs exclusively when antennae are stimulated with linalool [33]. Further studies revealed enantioselective responses of projection neurons (PNs) innervating adjacent female-specific glomeruli to $(R)-(-)$ - and $(S)-(+)$-linalool, which is not observed in general odorant-encoding glomeruli also found in male ALs [34]. These patterns suggest that feeding and oviposition are mediated by two separate neural channels in female $M$. sexta, the former via sexually isomorphic AL processing of racemic linalool and the latter 
through potentially inhibitory interactions between female-specific, enantioselective AL glomeruli [30]. This is precisely the kind of sensory/cognitive bias that flowering plants so adroitly manipulate in their ecological interactions with insect mutualists and antagonists [35], and likely explains why flowers of D. wrightii emit such low doses of (S)-(+)-linalool [24].

Recent studies have documented female-specific responses to $(S)-(+)$-linalool in the silk moth Bombyx mori [36] and enantio-specific responses (greater sensitivity to (R)-(-)-linalool) in the noctuid moth Mamestra brassicae [37], moths whose phylogenetic and ecological affinities differ markedly from those of $M$. sexta. These findings, along with the homologous nature of the olfactory receptor neurons that selectively respond to linalool [38], suggest a much broader relevance for this plant volatile and the selective pressures driving its perception by insect herbivores. Indeed, herbivory often induces systemic emission of linalool and other volatile terpenes (e.g. (E)- $\beta$-ocimene, $(E)$ - $\beta$-caryophyllene) in different plants [rev. by 39,40], in which linalool emissions may reduce further herbivory by inhibiting further oviposition [41] or by attracting natural enemies of the herbivores [42]. Although a detailed treatment of herbivoreinduced plant volatiles is well beyond the scope of this review, it is worth considering the many parallels between plant-pollinator and plant-herbivore interactions mediated by VOCs [43].

\section{Volatile versatility: from conventional signals to secret handshakes}

Two emerging themes in the study of chemical ecology are (a) that most secondary compounds have multiple and context-dependent functions, and (b) that many infochemicals appear to originate as deadly toxins which, through co-evolutionary processes, come to be utilized as signals and cues by organisms that evolve tolerance of them [44]. The available 
evidence suggests that these themes are equally relevant to the ecology and evolution of floral VOCs. At high dosages, linalool can be auto-toxic to plant cells. Attempts to engineer the overproduction of $(S)-(+)$-linalool in petunia flowers [45] and tomato fruits [46] resulted in the formation of linalool conjugates and 8-OH-linalool (see Arabidopsis, above), respectively. Linalool (in essential oils) is a potent control agent against the parasite responsible for Leishmaniasis [47] and Candida yeasts [48], and is among the most repellent floral VOCs in bioassays performed with two common ant species (Camponotus floridanus and Lasius fuliginosus) that opportunistically rob floral nectar [49; Figure 1C]. Junker and Blüthgen [50] expanded such assays to a large panel of floral scents, individual VOCs and a full spectrum of flower-visiting insects. The results of these assays led them to propose that obligate flowervisiting insects have evolved the ability to tolerate floral VOCs, in many cases utilizing them as attractants, whereas facultative flower visitors remain vulnerable to their toxicity, and are repelled by them.

What kind of information can linalool convey to obligate flower-visiting insects? One recent study demonstrated that variation in floral scent was significantly associated with seed fitness in a day-blooming, bee pollinated plant, Penstemon digitalis, identifying $(S)-(+)$-linalool as the target of phenotypic selection [51]. Further analyses identified the nectar spur as the source of this VOC [52], suggesting that $(S)$-(+)-linalool might function as an honest indicator of the presence of nectar, or might enhance floral constancy by pollinators, or might protect nectar from microbial infestation. Floral constancy is likely to result from a learned association of the consistent relationship between nectar availability and linalool, either as a scent or a flavor. If the bees that pollinate $P$. digitalis do not innately prefer $(S)-(+)-$ linalool, then this VOC would 
constitute a conventional honest signal, in the sense that bees could be conditioned on any perceivable, non-toxic volatile that accurately predicts nectar profitability [53].

In contrast, the obligate relationship between figs and fig wasps precludes such a relationship, as female fig wasps depart their natal fig with pollen loads and perish within the first receptive fig that they pollinate. Both fig and wasp lineages are hyper-diverse, and speciesspecific chemical signals have long been implicated as the key links to maintaining the specificity of their interactions [54]. To date, all fig species studied have been found to produce complex VOC blends dominated by monoterpene and sesquiterpene hydrocarbons, many of which have one or more stereocenters [55]. Studies focused on a tropical Asian species, Ficus hispida, revealed that its pollinator wasp, Ceratosolen solmsi is highly attracted to a 20:1 ratio of $(S)-(+)-$ linalool : (-)- $\beta$-pinene, but does not respond either to $(R)-(-)$-linalool or to other monoterpenes individually [56]. Thus, two common floral VOCs, in specific ratios of specific enantiomers, can mediate the most intimate of plant-pollinator interactions. However, these interactions do not occur in an ecological vacuum, and third parties often eavesdrop on such interactions. In a related fig species (Ficus racemosa), predatory ants (e.g. Oecophylla smaragdina) can learn to associate the VOCs of receptive figs with fig wasps as prey, whereas Myrmicaria brunnea ants, patrolling the same branches for honeydew, show no responses to fig volatiles [57].

\section{Conclusions}

Intensified study of floral volatiles has revealed a nuanced landscape of context-dependent interactions, in which critical details of chemical structure and function mediate ecological 
pattern and process. Given the multifunctional nature of linalool and the conflicting selective pressures brought to bear by floral mutualists and antagonists in response to its emission from flowers, this VOC would seem ideally suited to studies of geographic variation in phenotypic selection [58], in accordance with predictions of the Geographic Mosaic Theory of Coevolution, which outlines scenarios in which coevolutionary interactions should differ in the strength and direction of selection [59]. However, it should be clear from this review that linalool is not a special case, and we should expect most widespread floral volatiles to demonstrate a similar diversity of biological functions (see $[4,20]$ ). Finally, the discoveries reviewed here reveal how collaborative efforts between fields as disparate as plant molecular biology, insect neurophysiology and pollination ecology promise to unveil exciting new questions (e.g. [60]) as the study of floral volatiles enters the next phase of its evolution.

\section{References and Recommended Reading}

Papers of particular interest, published within the period of review, have been highlighted as

*Of special interest

** Of outstanding interest

\section{Acknowledgements}

I thank Eran Pichersky, Krissa Skogen and Amy Parachnowitsch for our shared explorations of floral linalool, Wittko Francke for expanding my awareness of stereocenters, Kjirsten Wayman for her stereo-editorial vision, May Berenbaum for the plenary invitation that stimulated this review and Mark Mescher and Consuelo de Moraes for the opportunity to publish it here. I 
gratefully acknowledge the support of the US National Science Foundation under grant DEB-

1342792.

\section{References}

1. Knudsen JT, Eriksson R, Gershenzon J, Ståhl B: Diversity and distribution of floral scent. The Botanical Review 2006, 72: 1-120.

2. Maia ACD, Dötterl S, Kaiser, R, Silberbauer-Gottsberger I, Teichert H, Gibernau M, do Amaral Ferraz Navarro DM, Schlindwein C, Gottsberger G: The key role of 4-methyl-5vinylthiazole in the attraction of scarab beetle pollinators: a unique olfactory floral signal shared by Annonaceae and Araceae. Journal of Chemical Ecology 2012, 38: 1072-1080.

3. Schäffler I, Steiner K, Haid M, van Berkel S, Gerlach G, Johnson SD, Wessjohann L, Dötterl S: Diacetin, a reliable cue and private communication channel in a specialized pollination system. Scientific Reports 2015, 5: 12779.

Doi:10.1038/srep12779.

** An elegant solution to a longstanding question in floral evolution, whether oil flowers signal the presence of oils to specialized oil bees with unique chemical signals. Remarkably, the authors identified an antennally active volatile, diacetin, which is an honest index of the presence of acylglycorol floral oils.

4. Raguso RA: Wake up and smell the roses: the ecology and evolution of floral scent. Annual Review of Ecology, Evolution, and Systematics, 2008: 549-569.

5. Schiestl FP: Ecology and evolution of floral volatile-mediated information transfer in plants. New Phytologist 2015, 206: 571-577.

6. Raguso RA, Pichersky E: A day in the life of a linalool molecule: chemical communication in a plant-pollinator system. Part 1: linalool biosynthesis in flowering plants. Plant Species Biology 1999, 14: 95-120.

7. Chen F, Tholl D, Bohlmann J, Pichersky E: The family of terpene synthases in plants: a mid-size family of genes for specialized metabolism that is highly diversified throughout the kingdom. The Plant Journal 2011, 66: 212-229.

8. Li G, Köllner TG, Yin Y, Jiang Y, Chen H, Xu Y, Gershenzon J, Pichersky E, Chen F: Nonseed plant Selaginella moellendorffii has both seed plant and microbial types of terpene synthases. Proceedings of the National Academy of Sciences 2012, 109: 14711- 
14715.

9. van Schie CC, Haring MA, Schuurink RC: Tomato linalool synthase is induced in trichomes by jasmonic acid. Plant molecular biology 2007, 64: 251-263.

10. Ginglinger JF, Boachon B, Höfer R, Paetz C, Köllner TG, Miesch L, Lugan R, Baltenweck R, Mutterer J, Ullmann P, Beran F: Gene coexpression analysis reveals complex metabolism of the monoterpene alcohol linalool in Arabidopsis flowers. The Plant Cell, 2013, 25: 4640-4657.

11. Steenhuisen SL, Raguso RA, Johnson SD: Floral scent in bird-and beetle-pollinated Protea species (Proteaceae): Chemistry, emission rates and function. Phytochemistry 2012, 84: 78-87.

12. Winterhalter P, Katzenberger D, Schreier P: 6,7-Epoxylinalool and related oxygenated terpenoids from Carica papaya fruit. Phytochemistry 1986, 25: 1347-1350.

13. Dötterl S, Burkhardt D, Weißbecker B, Jürgens A, Schütz S, Mosandl A: Linalool and lilac aldehyde/alcohol in flower scents: Electrophysiological detection of lilac aldehyde stereoisomers by a moth. Journal of Chromatography A, 2006, 1113: 231238.

14. Plepys D, Ibarra F, Löfstedt C: Volatiles from flowers of Platanthera bifolia (Orchidaceae) attractive to the silver Y moth, Autographa gamma (Lepidoptera: Noctuidae). Oikos 2002, 99: 69-74.

15. Dötterl S, Jürgens A, Seifert K, Laube T, Weißbecker B, Schütz S: Nursery pollination by a moth in Silene latifolia: the role of odours in eliciting antennal and behavioural responses. New Phytologist 2006, 169: 707-718.

16. Okamoto T, Okuyama Y, Goto R, Tokoro M, Kato M: Parallel chemical switches underlying pollinator isolation in Asian Mitella. Journal of evolutionary biology 2015, 28: 590-600.

* Mitella flowers are tiny, and they require tiny pollinators. The authors combined electrophysiological, behavioral and phylogenetic approaches to document repeated pollinator shifts from long to short tongued fungus gnats as pollinators, mediated by the loss of lilac aldehydes, which attract the former and repel the latter.

17. Boachon B, Junker RR, Miesch L, Bassard JE, Höfer R, Caillieaudeaux R, Seidel DE, Lesot A, Heinrich C, Ginglinger JF, Allouche L: CYP76C1 (Cytochrome P450)mediated linalool metabolism and the formation of volatile and soluble linalool oxides in Arabidopsis flowers: a strategy for defense against floral antagonists. The Plant Cell 2015, 27: 2972-2990. 
** A tour de force of integrative research on floral volatiles, establishing in vivo functions and behavioral consequences for linalool metabolism in a flower that does not need to attract pollinators. This study connects the dots between decades of fragmentary research on VOC oxidation, conjugation and detoxification in plant cells.

18. Raguso RA: Floral scent in a whole-plant context: moving beyond pollinator attraction. Functional Ecology 2009, 23: 837-840.

19. Kessler D, Gase K, Baldwin IT: Field experiments with transformed plants reveal the sense of floral scents. Science 2008, 321: 1200-1202.

20. Galen C, Kaczorowski R, Todd SL, Geib J, Raguso RA: Dosage-dependent impacts of a floral volatile compound on pollinators, larcenists, and the potential for floral evolution in the alpine skypilot Polemonium viscosum. The American Naturalist 2011, 177: $258-272$.

21. Kessler D, Diezel C, Clark DG, Colquhoun TA, Baldwin IT: Petunia flowers solve the defence/apparency dilemma of pollinator attraction by deploying complex floral blends. Ecology Letters 2013, 16: 299-306.

22. Kaiser R: The scent of orchids: olfactory and chemical investigations. Elsevier Science Publishers BV 1993.

23. Knudsen JT, Tollsten, L: Trends in floral scent chemistry in pollination syndromes: floral scent composition in moth-pollinated taxa. Botanical Journal of the Linnean Society, 1993, 113: 263-284.

24. Riffell JA, Lei H, Hildebrand JG: Neural correlates of behavior in the moth Manduca sexta in response to complex odors. Proceedings of the National Academy of Sciences, 2009, 106: 19219-19226.

25. Adler LS, Bronstein JL: Attracting antagonists: does floral nectar increase leaf herbivory? Ecology 2004, 85: 1519-1526.

26. Kessler D: Context dependency of nectar reward-guided oviposition. Entomologia Experimentalis et Applicata 2012, 144: 112-122.

27. von Arx M, Sullivan KA, Raguso RA: Dual fitness benefits of post-mating sugar meals for female hawkmoths (Hyles lineata). Journal of insect physiology 2013, 59: 458-465.

28. Sloan SA, Zimmerman JK, Sabat AM: Phenology of Plumeria alba and its herbivores in a tropical dry forest. Biotropica 2007, 39: 195-201.

29. Bronstein JL, Huxman T, Horvath B, Farabee M, Davidowitz G: Reproductive biology of Datura wrightii: the benefits of a herbivorous pollinator. Annals of Botany 2009, 103: $1435-1443$. 
30. Reisenman CE, Riffell JA, Bernays EA, Hildebrand JG: Antagonistic effects of floral scent in an insect-plant interaction. Proceedings of the Royal Society of London B: Biological Sciences 2010, 277: 2371-2379.

* An important study that provides behavioral context for a decade of neuroanatomical and physiological studies of enantiospecific odorant coding in the hawkmoth antennal lobe. This study underscores the hazards of assuming the most abundant floral volatiles to be the most behaviorally active, as both linalool enantiomers are emitted in trace amounts by Datura flowers.

31. Reisenman CE, Riffell JA, Duffy K, Pesque A, Mikles D, Goodwin B: Species-specific effects of herbivory on the oviposition behavior of the moth Manduca sexta. Journal of Chemical Ecology, 2013, 39: 76-89.

32. Späthe A, Reinecke A, Olsson SB, Kesavan S, Knaden M, Hansson BS: Plant speciesand status-specific odorant blends guide oviposition choice in the moth Manduca sexta. Chemical Senses 2013, 38: 147-159.

33. King JR, Christensen TA, Hildebrand JG: Response characteristics of an identified, sexually dimorphic olfactory glomerulus. The Journal of Neuroscience 2000, 20: 23912399.

34. Reisenman CE, Christensen TA, Francke W, Hildebrand JG: Enantioselectivity of projection neurons innervating identified olfactory glomeruli. The Journal of Neuroscience 2004, 24: 2602-2611.

35. Schaefer HM, Ruxton GD: Deception in plants: mimicry or perceptual exploitation? Trends in Ecology \& Evolution 2009, 24: 676-685.

36. Anderson AR, Wanner KW, Trowell SC, Warr CG, Jaquin-Joly E, Zagatti P, Robertson $\mathrm{H}$, Newcomb RD. Molecular basis of female-specific odorant responses in Bombyx mori. Insect Biochemistry and Molecular Biology 2009, 39: 189-197.

37. Ulland S, Ian E, Borg-Karlson AK, Mustaparta H: Discrimination between enantiomers of linalool by olfactory receptor neurons in the cabbage moth Mamestra brassicae. Chemical Senses 2006, 31: 325-334.

38. Große-Wilde E, Kübler LS, Bucks S, Vogel H, Wicher D, Hansson BS: Antennal transcriptome of Manduca sexta. Proceedings of the National Academy of Sciences 2011, 108: 7449-7454.

39. Kessler A, Halitschke R: Specificity and complexity: the impact of herbivore-induced plant responses on arthropod community structure. Current Opinion in Plant Biology 2007, 10: 409-414.

40. Dicke M, Baldwin IT: The evolutionary context for herbivore-induced volatiles: beyond the 'cry for help'. Trends in Plant Science 2010, 15, 167-175. 
41. DeMoraes CM, Mescher MC, Tumlinson JH: Caterpillar-induced nocturnal plant volatiles repel conspecific females. Nature 2001, 410: 577-580.

42. Kessler A, Baldwin IT: Defensive function of herbivore-induced plant volatile emissions in nature. Science 2001, 291: 2141-2144.

43. Lucas-Barbosa D, van Loon JJ, Dicke M: The effects of herbivore-induced plant volatiles on interactions between plants and flower-visiting insects. Phytochemistry 2011, 72: 1647-1654.

44. Raguso RA, Agrawal AA, Douglas AE, Jander G, Kessler A, Poveda K, Thaler JS: The raison d'être of chemical ecology. Ecology 2015, 96: 617-630.

45. Lücker J, Bouwmeester HJ, Schwab W, Blaas J, van der Plas LH, Verhoeven HA:

Expression of Clarkia $\mathrm{S}$-linalool synthase in transgenic petunia plants results in the

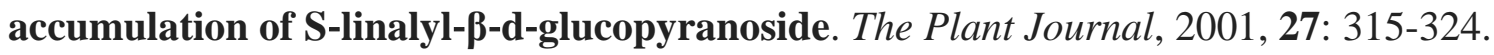

46. Lewinsohn E, Schalechet F, Wilkinson J, Matsui K, Tadmor Y, Nam KH, Amar O, Lastochkin E, Larkov O, Ravid U, Hiatt W: Enhanced levels of the aroma and flavor compound $\mathrm{S}$-linalool by metabolic engineering of the terpenoid pathway in tomato fruits. Plant Physiology 2001, 127: 1256-1265.

47. Maria do Socorro SR, Mendonça-Filho RR, Bizzo HR, de Almeida Rodrigues I, Soares RMA, Souto-Padrón T, Sales Alviano C, Hampshire A, Lopes CS: Antileishmanial activity of a linalool-rich essential oil from Croton cajucara. Antimicrobial Agents and Chemotherapy 2003, 47: 1895-1901.

48. Alviano WS, Mendonça-Filho RR, Alviano DS, Bizzo HR, Souto-Padrón T, Rodrigues ML, Bolognese AM, Alviano CS, Souza MMG: Antimicrobial activity of Croton cajucara Benth linalool-rich essential oil on artificial biofilms and planktonic microorganisms. Oral Microbiology and Immunology 2005, 20: 101-105.

49. Junker RR, Blüthgen N: Floral scents repel potentially nectar-thieving ants. Evolutionary Ecology Research 2008, 10: 295-308.

50. Junker RR, Blüthgen N: Floral scents repel facultative flower visitors, but attract obligate ones. Annals of Botany 2010, 105: 777-782.

51. Parachnowitsch AL, Raguso RA, Kessler A: Phenotypic selection to increase floral scent emission, but not flower size or colour in bee-pollinated Penstemon digitalis. New Phytologist 2012, 195: 667-675.

52. Burdon RC, Raguso RA, Kessler A, Parachnowitsch AL: Spatiotemporal floral scent variation of Penstemon digitalis. Journal of Chemical Ecology 2015, 41: 641-650. 
53. Knauer AC, Schiestl FP: Bees use honest floral signals as indicators of reward when visiting flowers. Ecology Letters 2015, 18: 135-143.

54. Grison-Pigé L, Bessière JM, Hossaert-McKey M: Specific attraction of fig-pollinating wasps: role of volatile compounds released by tropical figs. Journal of Chemical Ecology 2002, 28: 283-295.

55. Hossaert-McKey M, Soler C, Schatz B, Proffit M: Floral scents: their roles in nursery pollination mutualisms. Chemoecology 2010, 20: 75-88.

56. Chen C, Song Q: Responses of the pollinating wasp Ceratosolen solmsi marchali to odor variation between two floral stages of Ficus hispida. Journal of Chemical Ecology, 2008, 34: 1536-1544.

57. Ranganathan Y, Borges RM: Predatory and trophobiont-tending ants respond differently to fig and fig wasp volatiles. Animal Behaviour 2009, 77: 1539-1545.

58. Gross K, Sun M, Schiestl FP: Why do floral perfumes become different? Regionspecific selection on floral scent in a terrestrial orchid. PloS one 2016, 11: e0147975.

59. Thompson JN: Specific hypotheses on the geographic mosaic of coevolution. The American Naturalist, 1999, 153: S1-S14.

60. Saveer AM, Kromann SH, Birgersson G, Bengtsson M, Lindblom T, Balkenius A, Hansson BS, Witzall P, Becher PG, Ignell R: Floral to green: mating switches moth olfactory coding and preference. Proceedings of the Royal Society of London B: Biological Sciences 2012: rspb20112710.

**This study answered one trivial question (why don't Spodoptera moths behave in wind tunnels?) and one profound one (what are the neural correlates of behavioral shifts from nectar foraging to host plant selection in mated females?), using calcium imaging and single sensillum recording to track AL and antennal responses to linalool and lilac compounds emitted by lilac flowers. 


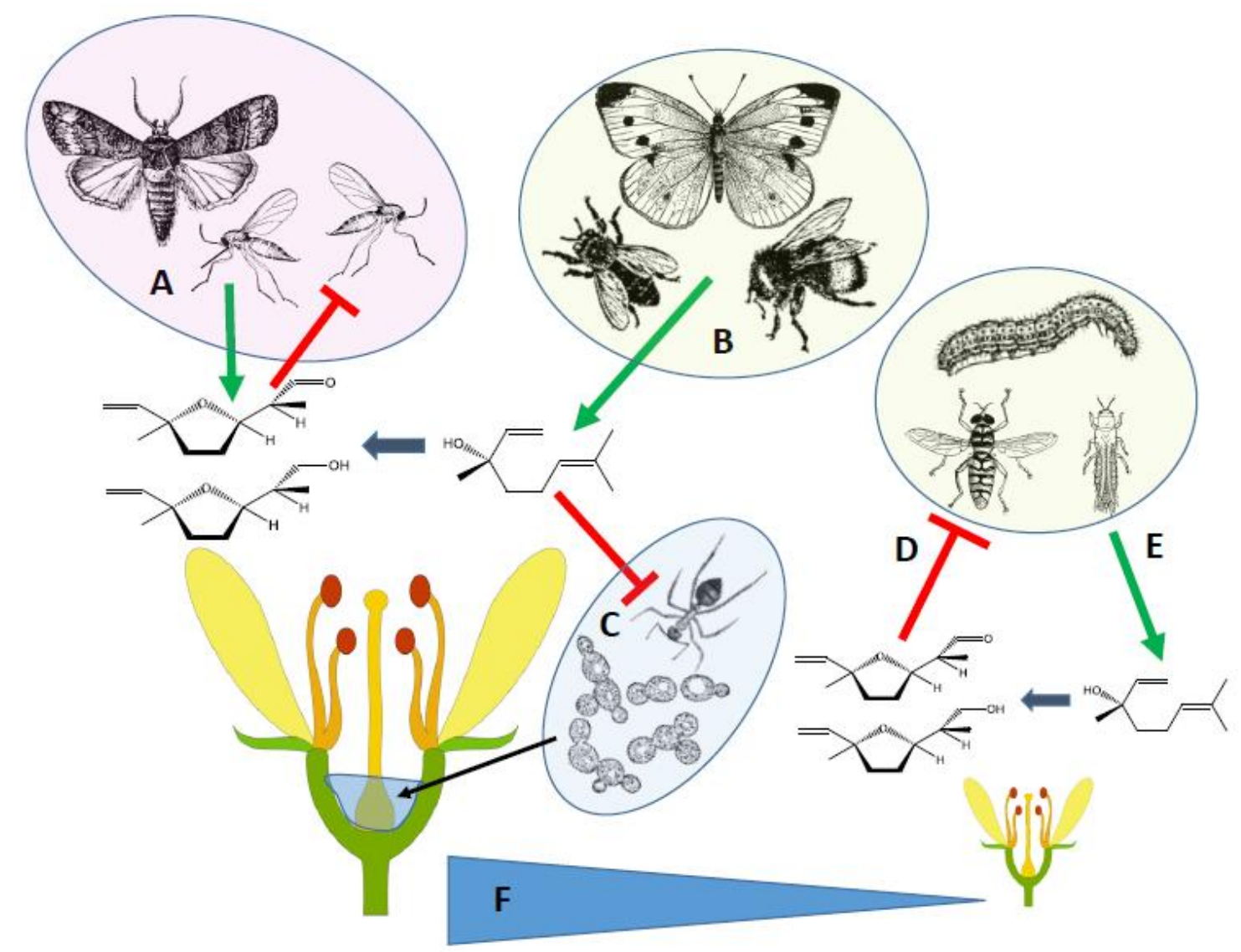

Figure 1: Schematic diagram of floral filters mediated by linalool metabolism, represented here by conversion of $(R)-(-)$-linalool (right of the blue arrow) to lilac aldehydes and alcohols (left of the blue arrow). Blue arrows represent biosynthetic transformation, green arrows indicate attraction and red piston-ended lines indicate repellence. A: attraction of specialized pollinators (noctuid moths, long tongued fungus gnats - and repellence of short tongued gnats) by lilac compounds [14,16], B: attraction of generalized pollinators (bees, butterflies) by linalool [42], C: (hypothesized) exclusion of ants [42] and yeasts [40] by linalool solved in nectar, D, E: repellence of facultative visitors to Arabidopsis thaliana flowers by lilac compounds and attraction of same by linalool [17]. F: decreasing dependence upon pollinators to effect reproductive success, from a nectar-bearing allogamous flower on the left (e.g. Silene latifolia [15]) to an unrewarding autogamous flower on the right (e.g. A. thaliana [17]). Visitor images 
are used courtesy of ClipArt ETC (http://etc.usf.edu/clipart/). Flower images are used courtesy of Wikimedia Commons (https://commons.wikimedia.org). 